\title{
Física da Oscilação de Neutrinos
}

\author{
Juliana T. de Araújo*, Orlando L. G. Peres
}

\begin{abstract}
Resumo
Neste trabalho introduzimos o formalismo da teoria de oscilação de neutrinos e apresentamos a probabilidade de sobrevivência para duas famílias no vácuo, na matéria uniforme e não uniforme. Consideramos também o caso de três neutrinos no vácuo. Nesse modelo, o neutrino pode ser escrito como uma mistura de sabores, o que faz com que a partícula oscile entre as três famílias durante seu trajeto. Esse fenômeno pode resolver o problema do neutrino solar, que constatou um desaparecimento no fluxo de neutrinos eletrônicos, mas não no fluxo total (levando em conta a contribuição de todos os sabores). Ao calcular as probabilidades, vemos que elas dependem da diferença do quadrado das massas, o que vai de encontro com o Modelo Padrão, pois este não previa massa para os neutrinos.
\end{abstract}

\section{Palavras-chave:}

Neutrinos, oscilação, mistura de sabores.

\section{Introdução}

Os neutrinos são léptons com massa muito pequena que não possuem carga elétrica e, embora sejam muito abundantes no universo, interagem muito pouco com a matéria. Eles podem ser classificados em três sabores: neutrino do elétron, múon e tau, sendo que o primeiro tipo é abundantemente produzido no Sol.

Muitos experimentos tentaram medir o fluxo de neutrinos solares que chegavam na Terra, detectando menos partículas do que o previsto pelo Modelo Solar Padrão. Contudo, o Sudbury Neutrino Observatory $(\mathrm{SNO})^{1}$ mediu o fluxo total de neutrinos solares, obtendo um resultado de acordo com a previsão teórica. Assim, para explicar os resultados experimentais, foi proposto 0 fenômeno de oscilação de sabores, em que o neutrino pode ser escrito como uma mistura de sabores. Isso faz com que o neutrino oscile entre as três famílias durante sua trajetória. A principal consequência desse modelo é o requerimento da massa do neutrino, fato que não era considerado pelo Modelo Padrão.

$\mathrm{Na}$ teoria de oscilação em três famílias, há um parâmetro ainda não determinado que descreve a violação de simetria carga-paridade (CP), a qual acredita-se ser a causa do universo ter mais matéria do que anti-matéria. Assim, investigações para a confirmação de violação de CP na oscilação de neutrinos são muito importantes, pois seria um grande passo para explicar a assimetria bariônica no universo.

O objetivo desse trabalho é apresentar a fundamentação teórica do modelo e calcular a probabilidade de ocorrer oscilação no vácuo considerando conversão entre dois e três sabores, bem como na matéria uniforme e não uniforme para duas famílias.

\section{Resultados e Discussão}

$\mathrm{Na}$ teoria de oscilação existem os neutrinos físicos (auto-estados de propagação ou de massa) com massas $m_{1}, m_{2}$ e $m_{3}$ bem definidas e os neutrinos de sabor (auto-estados de interação). Eles formam duas bases, cujas componentes se relacionam da forma:

$$
v_{\alpha}=\sum_{i=0}^{3} U_{\alpha i} v_{i}, \text { onde } \alpha=e, \mu o u \tau
$$

e U é uma matriz unitária que depende do ângulo de mistura, da diferença do quadrado das massas e, para três neutrinos, também da fase de violação de CP $(\delta)$.

Para obtermos a probabilidade de sobrevivência, precisamos resolver a equação de Schrödinger utilizando o Hamiltoniano do meio em questão. Assim, para o caso do vácuo e considerando apenas dois sabores, temos:

$$
P_{e e}=1-\operatorname{sen}^{2} 2 \theta \operatorname{sen}^{2}\left(\Delta m^{2} x / 4 E\right)
$$

$\mathrm{Na}$ matéria uniforme, a fórmula é análoga, apenas substituindo a diferença de massas e o ângulo de mistura pelos mesmos parâmetros na matéria. Já para a matéria não uniforme no regime adiabático, onde $d \widetilde{\theta} / d x \approx 0$, e sem considerar a interferência quântica, temos (onde o '0' significa posição de origem):

$$
P_{e e}^{(a d)}=1 / 2\left(1+\cos 2 \widetilde{\theta_{0}} \cos 2 \theta\right)
$$

$E$ no regime não adiabático, no qual pode haver transições entre os estados $\widetilde{v}_{1}$ e $\widetilde{v}_{2}$, temos:

$$
P_{e e}=1 / 2\left[1+(1-2 X)^{2} \cos 2 \widetilde{\theta_{0}} \cos \theta\right],
$$

onde $X$ é a probabilidade de haver transição entre $\widetilde{v}_{1}$ e $\widetilde{v}_{2}$. Por fim, se $\Delta \mathrm{m}^{2}{ }_{31} \approx \Delta \mathrm{m}^{2}{ }_{32}, \mathrm{P}_{\mathrm{ee}}$ no vácuo para $3 v$ :

$$
\begin{array}{r}
P_{e e}=1-\operatorname{sen}^{2}\left(2 \theta_{12}\right) \cos ^{4} \theta_{13} \operatorname{sen}^{2}\left(\Delta m^{2}{ }_{21} / 4 E\right) \\
-\operatorname{sen}^{2}\left(2 \theta_{13}\right) \operatorname{sen}^{2}\left(\Delta m^{2}{ }_{32} / 4 E\right)
\end{array}
$$

\section{Conclusão}

Portanto, a principal consequência do modelo é que a oscilação é induzida pela diferença de massa dos neutrinos. Além disso, verificamos da equação (2) que o comprimento de oscilação aumenta com a energia e diminui com o aumento de $\Delta \mathrm{m}^{2}$. Já para a matéria não uniforme, não temos de fato uma oscilação, pois a probabilidade de sobrevivência não evolui com a distância. Por fim, temos que a equação (5), para o caso do elétron, se reduz à probabilidade para dois neutrinos quando fazemos a aproximação $\theta_{13}<1$, o que de fato ocorre na natureza.

\section{Agradecimentos}

Agradeço ao professor Orlando Peres por me orientar e ao CNPq por ter apoiado e fomentado esse projeto. 